\title{
A Decision-Making Perspective for Designing and Building Information Systems
}

\author{
F.G. Filip
}

\author{
Florin Gheorghe Filip \\ The Romanian Academy: BAR and INCE, \\ and the Nat. Inst. for R\&D in Informatics -ICI, \\ Bucharest, Romania \\ ffilip@acad.ro
}

\begin{abstract}
This paper aims at highlighting several aspects and associated decision situations which may be met in the process of designing and building modern information systems, such as: choosing the approach and methods to be utilized for building the system and selecting the IT tools, integrating the system into the enterprise and evaluating the project. A particular emphasis is put on evaluation criteria to be utilized in solving the various decision problems. Keywords: decision criteria, IT\&C tools, methodology, prototype, SaaS, standards.
\end{abstract}

\section{Introduction}

A large number of models and corresponding solvers have been proposed and reported in the literature with a view to getting optimal solutions for the academic test-problems or real-world management and control applications. They can be found in the technical literature. In many cases, in practical applications, a necessary condition to make the models and the corresponding solvers utilized is to incorporate them into adequate information systems (IS).

In the same time, the IT\&C (information technology and communication) vendors release to the market ever more modern hardware and software products. New trends can be noticed on the software market [21], such as "merger mania" (consisting in mergers, acquisitions, partnerships and strategic alliances between business software vendors), functional expansion, a clear dominance of a few (three) databases (Oracle, Microsoft SQL Server, and IBM DB2), increased usage of Internet, viewing IT/software as a service and so on. Exhaustive services for project management in the software field to serve those managers who want to save time are already available on the market [18].

One can notice, during the process of designing and implementing information systems, sequences of decisions which should be made with respect to the choice of the most adequate alternatives concerning several critical aspects, such as system orientation, composition of the team, method to be adopted, IT\&C tools to be utilized, resources to be allocated and so on. In this context, this paper aims at surveying from a decision-making perspective several methodological and practical aspects of designing effective (usable, useful, and actually utilized) IS. The paper extends, details and up-dates an earlier preliminary version of the paper [9]. The remaining part of this paper is organized as it follows. In the second section, several factors which may influence decisions meant to design and implement information systems in organizations are reviewed. Then, several design and implementation critical aspects are presented, such as the design approach adopted and the selection of the IT\&C tools. The paper concludes with a discussion of technical and non-technical integration issues and evaluation aspects. Throughout the paper the evaluation criteria to be used in various decisions are highlighted. 


\section{Main Influence Factors}

There are several factors which can influence the process of designing and implementing an information system, such as: people involved, the orientation and the purpose of the system, the organizational setting, standards utilized and so on [8]. Those influence factors should be taken into consideration by the management of the target enterprise and the designer as well, when a decision on introducing and creating an information system is to be made.

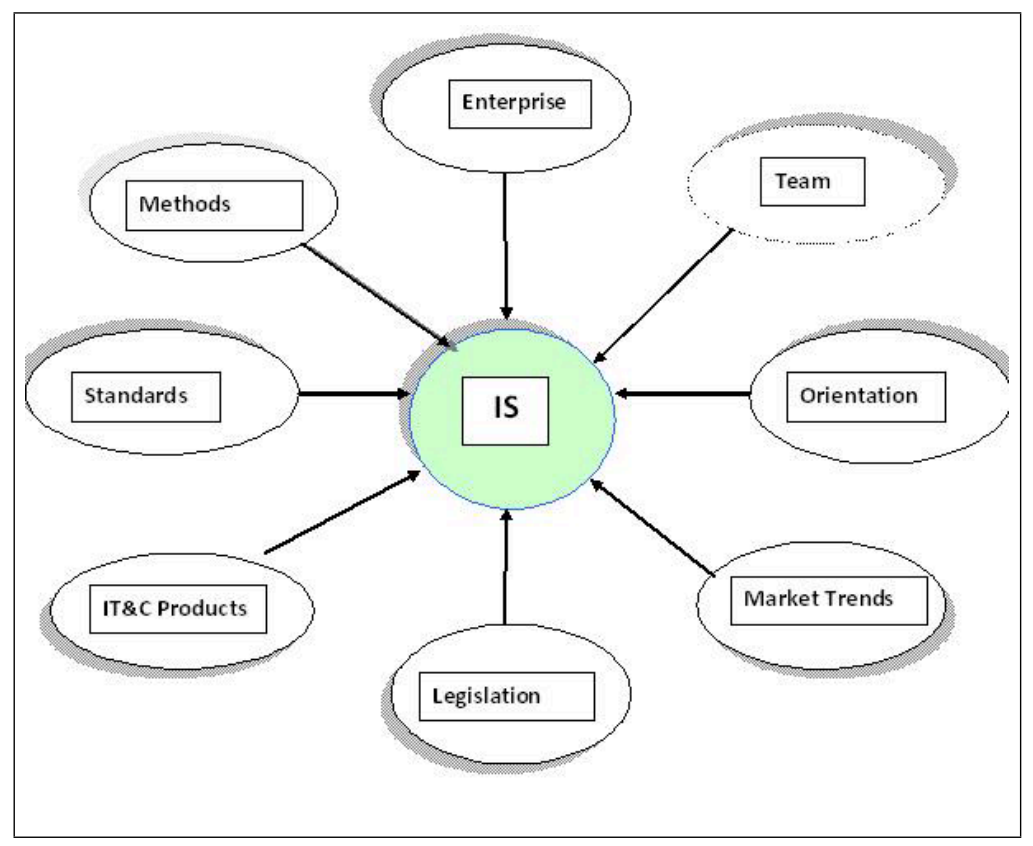

Figure 1: Influence factors (adapted from [9])

The people involved in the IS design and implementation should cooperate closely to form a virtual team who aims at obtaining the best solution for the allocated resources (time, manpower, money). There are several classes of people who should take part in various extents of involvement and contributions to the process for the first moment of discussing the idea of IS until its "steady state" operation and impact evaluation. One can identify the following generic classes:"clients", designers, and IT\&C vendors. The members of the "client" class include the project "sponsor" (a manager) and the project "champion" who represents the interests of the future direct ('hands-on") or indirect ("beneficiary") actual users ( who may be also involved in design and implementation of the IS). The "project champion" possesses the necessary knowledge of the application domain. The "project sponsor" possesses the authority since he/she represents the interests of the organization and, consequently, is empowered to accept or reject the project solutions and allocate the necessary resources. The designers can be members of a group of people of the organization or/and a team of analysts and IT\&C professionals from a consultancy firm who master the design techniques and who are aware of the IT\&C products available on the market. The IT\&C manufacturers and vendors can adapt and alter the IT\&C products to be utilized.

The information system may be oriented to serve a certain generic class of users ("roles") or to help a specific group of persons with names, identities and specific IT skills ("actors").

The system purpose might be either to facilitate and make more comfortable the work of 
the users, or to promote the change. The normative model of the change [14] includes several steps of cooperation between users and designers which can be met in the process of creating an information system, such as:

- Pioneering (to evaluate the needs of the final users and necessary competences of the systems constructors);

- Acceptance (to establish the objectives to be agreed by the users and the designers);

- Diagnosis (to collect the data, define the problem and estimate the necessary resources);

- Planning (to set up the work plan and allocate the corresponding resources);

- Action (to design and implement the information system and train its users);

- Evaluation of the process and project impact.

The target organization where the information system is to be implemented may create a context which strongly influences the solution and the process of the system building. There might be constraints caused by a) the insufficient IT\&C knowledge and skills of the future users and b) scarce available data or/and limited internal data access rights of the external consultants. Several integration problems may show up caused by the "legacy IT systems" or/and the operating procedures permitted within the organization.

Standards should play a central role in design. The International Standard Organization (ISO) is an excellent source of documents to be utilized to set the stage for useful, usable and used solutions. The standards for usable (traditionally called "user-friendly") interfaces, such as those of the series [13]ISO 9241 ("Ergonomics of Human-System Interaction"), are recommended and can contribute to obtaining a user-centered solution. The quite recent standards, such as ISO 9241-171.2008 ("Guidance in Software Accessibility") and ISO 9241-151.2008 ("Guidance WWW User Interface"), are of a particular importance in the context of modern information systems which are ever more oriented to use www technologies. Suduc [23] gives a comprehensive analysis of the design methods to be utilized in the low-cost interface design. Cojocaru [5] proposes the intelligent interface concept.

Other aspects, such as previous experience, industry competitors' moves, legislation and, the most serious one, available budgets and intended due dates, may also influence the IS construction process.

\section{Design and Implementation Approaches}

There are various approaches to designing, building and implementing an information system. They can be grouped in accordance with several criteria, such as:

- IT\&C tools and platforms which will be utilized (general-purpose products vs integrated suites/generators/shells);

- Buying IT or using IT as a Service-ITaS [11], or Software as a Service -SaaS [4] and [25];

- Place for construction (within the target organization or at the consultant's site);

- Method utilized (the lifecycle method or the evolving/adaptive design which is based on the use of the prototype).

The lifecycle-based method requires several steps, such as system analysis, design, implementation, and operation which are carried out in sequential ("cascade") manner. It also implies that the well defined procedures and checkpoints are strictly observed and the solutions adopted are well documented. It is, consequently, recommended for large-scale applications. 
The origins of the prototype-based method [20] in the field of IS could be traced back in mid 70 's in the empiric remark that $80 \%$ of the design ideas in the field are wrong [17]. Consequently, in order to avoid the waste of resources, the prototype permitted to spend $20 \%$ of the resources in the early stages of design and construction for identifying the $80 \%$ wrong ideas, so that the remaining $80 \%$ of resources should be utilized to implement the remaining $20 \%$ of ideas which are likely to be correct.

When adopting the prototype-based method, there are a few basic principles which are to be observed such as:

- The process starts with approaching the most critical problems of the target organization, so that the user's confidence could be gained as early as possible. In some cases, a "demo script", which includes a critical business scenario [21], can be also utilized to select the most adequate product from a short list (see the next section);

- The early requirements can be formulated in collaboration with the user in a "quick and dirty "simplified manner;

- The information system is developed in several cycles which include operations, such as experiment, evaluation, modification. The cycles should be as short as possible and the cost of the first version must be very low, in order not to lose the user's interest and confidence;

- The evaluation of the effects of the usage of the preliminary version is carried out on a permanent time basis.

Two main types of prototypes have been commonly utilized [22]: a) the "throwaway" prototype, and b) the "evolving one". While the former is only utilized to test the design ideas and then is discarded ( the next versions re-designed by using new technologies), the latter consists in a series of refinements of the initial version (Fig. 2). A decision choice should be made on which type to be utilized.

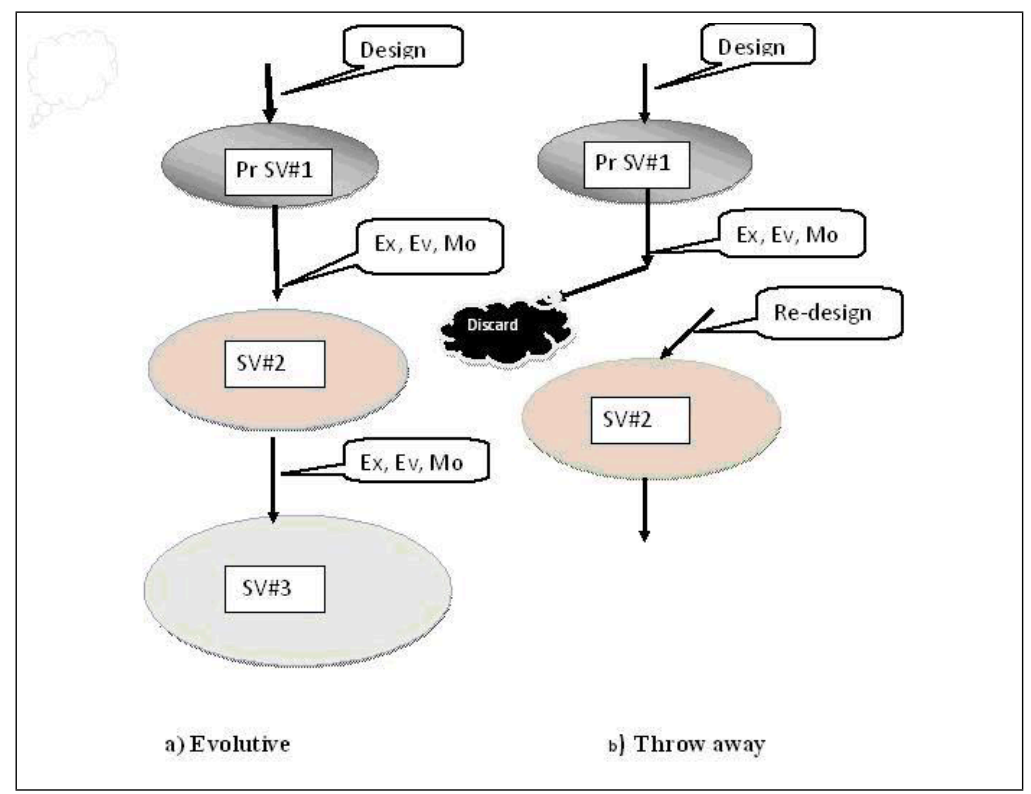

Figure 2: Types of prototypes (Legend: $\mathrm{Pr}=$ prototype, $\mathrm{SV}=$ System version, $\mathrm{Ex}=$ Experiment, $\mathrm{Ev}=$ Evaluate, $\mathrm{Mo}=$ Modify)

The prototype-based (adaptive/incremental/iterative) methods allow for obtaining a good well customized, early utilizable and helpful solution, even if the information on organization 
and its context is scarce and uncertain. On the other hand, methods may stimulate the tendency to continually modify the solution or, on the contrary, to adopt too early a solution which is imperfect or incomplete. In [6] and [8] the story of constructing DISPATCHERß, a family of Decision Support Systems (DSS) which is meant to assist logistics and production control decisions to be made in the context of the continuous process industries and related fields, is described. The DISPATCHERß project started in early 80 's as an optimization model and software for production scheduling. Since then, under the influence of several factors such as the users' changing needs and improvement of their IT\&C skills, specific characteristic features of target enterprises, and new products and technologies released in the field of IT\&C, several application versions were designed and installed in refineries, pulp and paper mills, chemical plants,

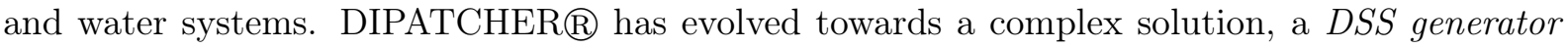
which could be adapted to new business models (such as the "extended"/networked/"virtual" enterprise), to support new functions and usages. It includes new constituents, such as a threelevel modeling scheme of the plant (expressed in terms of final users, analysts and programmers, respectively), AI (Artificial Intelligence)-based solvers and model experimentation tools( Fig. 3).

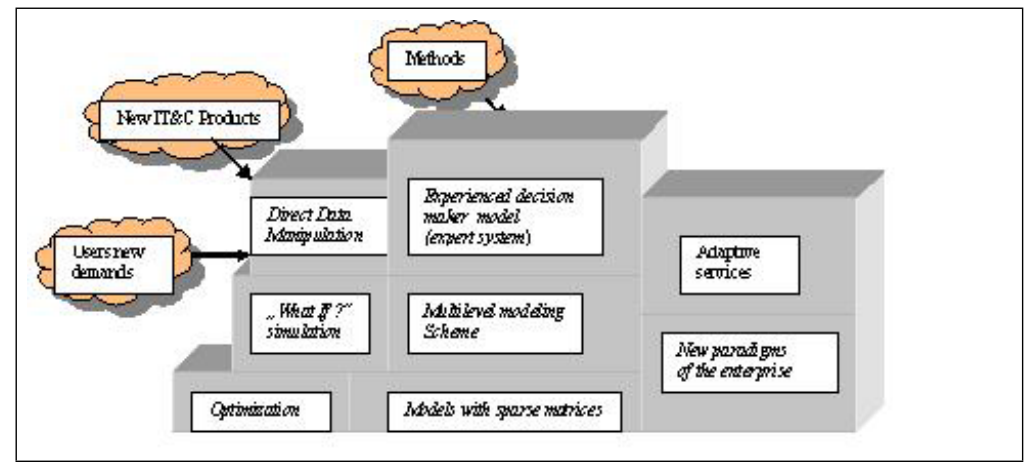

Figure 3: Evolution of Dispatcher system (adapted from [6] and [9])

An important decision consists in making a choice between buying or leasing IT\&C products. For example, in recent years, the approach to use SaaS (Software as a Service) model has become ever more popular. This new business model means that the software vendors host on their servers the applications to be accessed, via internet, by client organizations only when it is necessary. The pricing scheme is based on paying monthly lease fees, instead of initial license cost and annual maintenance fee. The SaaS scheme can be of particular interest for smaller companies that have limited IT infrastructure and skilled personnel. On the other hand, when a decision is to be made one should take into account long run costs and security issues. Availability of necessary IT infrastructure, ease of usage are the main evaluation criteria when a decision is to be made.

\section{Selection of the IT\&C Tools}

The selection of the IT\&C tools should be viewed as a multi-attribute decision-making (MADM) problem ( [12], [7], [19], [15]). The general criteria to be used in selecting and ranking the possible IT\&C products which can be found on the market can be grouped as it follows:

- Adequacy: informational transparency, accuracy of expected results, robustness to errors and low quality uncertain input data, response time;

- Quality of implementation: scalability, flexibility, easy integration with the "legacy systems", functional transparency, documentation completeness; 
- Delivery quality: price, delivery time, provider's general reputation, easy adaptation, degree on dependence on the technical assistance from the provider's specialists for implementation and usage).

A particular attention has been received by the software selection. A set of criteria for filtering the software products from the initial long list is recommended by Software Resources [21], such as: a) budget for the new system, b) unique functionality (i.e. multi-currency, multi-company, budgeting, workflow), c) technology preferences, d) reporting, e) scalability, and f) vendor stability. As a subsequent step to make a choice from the short list Software resources recommends the "scripted (or the standard) demo" in order to determine the software vendor or the VAR (value added reseller) to modify their product demo to show how the specific business needs of the client can be solved. A systematic methodology for software evaluation and selection through the usage of MADM was proposed by [16] and an experimental expert system was proposed by $[27]$.

An interesting list of pitfalls to be avoided when selecting the software is provided by Software Resources [21]. It includes the following 12 "deadly mistakes": "a) buying the same software as the competitors, b) buying software based on features alone, and overlooking other critical factors (scalability, flexibility, excessity, technology and cultural fit, affordable cost, insufficient technical support and infrastructure), c) neglecting the proper consideration of the vendor reputation, d) buying software without focusing on the implementation partner, e) taking into consideration only the low initial costs and overlooking significantly higher ongoing costs, f) buying software using input from an elite group without getting buy-in from the organization at large, g) choosing the popular software without considering all the posible and affordable options $h$ ) buying software that is too complex, i) making a choice without properly defining your requirements, $\mathrm{j}$ ) buying software that is either at the end or at the beginning of its product lifecycle, $\mathrm{k}$ ) buying software that is based on dying technology, l) selecting a software only to fix the current business problems" (instead of implementing the change).

Comprehensive on-line independent support for software evaluation and selection can be obtained from specialized consulting firms, such as Technology Evaluation Center [24], Software Resources [21], Project Perfect [18].

\section{Integration}

In many cases a new information systems should be integrated into the existing or planned IT\&C infrastructure of the target organization. Several principles are recommended by [26] which are still valid for technical integration, such as:

- Adopting an "open system" architecture;

- Neutralizing the information which can be achieved by using standardized data formats;

- Semantic unification which means a symbol has a unique meaning throughout the whole system.

There are, however, several new problems which can show up due to non-technical causes, for example:

- Wrong orientation of the solution which does not facilitate solving the central problems of the organization; this may be associated with informational opacity (the system provides more/less than necessary outputs); 
- Functional opacity which means that he user is not given the necessary information and incentives to understand how the system works;

- Frustration of the "hands-on" user due to a long response time or an un-adequate (insufficient/excessive) number of functions to perform his/her task.

\section{Evaluation}

Evaluation of IS has been subject of interest for long time [10]. There are several main principles to be observed in the process of designing, building and implementing an information system, such as:

- Evaluation is necessary all over in the design and implementation process to support making a decision choice from the set of possible alternatives (project continuation, giving up, allocating some additional resources and so on);

- The objectives and the degree of detail of evaluation depend on various factors, as : a) the project scope, b) technical complexity, c) duration and cost of the project, d) the person who requested the evaluation, e) overall state of the target enterprise;

- Involving the designer into the evaluation team is necessary especially in the case of a large project.

As previously stated, the evaluation is meant to support a decision-making process. Consequently, a set of evaluation criteria should be set up, namely:

- Impact on the efficiency of users' professional performance in accomplishing his/her tasks and quality of life (intellectual development, possible additional stress caused, comfort of performing the task);

- Impact on target enterprise general evolution;

- Implementation and further running costs.

A set of more detailed set of criteria which was used in a specific context is given by [1].

There are several methods which can be utilized for evaluation, for example: a) benefits/cost analysis, though the NVP ("net present value") of the investments, b) value analysis, c)"rating and scoring", d) event logging and so on. Agouram [2] gives a useful methodology to assess the IS success.

\section{Conclusion}

The activities of designing and implementing an information system form, in practical applications, a process which may include many decisions to be made at different stages. There are several critical aspects, both of the technical and non-technical nature, which should be taken into consideration. Among the main aspects which might cause problems are the evolution of the technical constituents associated with the increased requirements for the solution quality set by the users who are ever more informed and skilled and have to face an ever more fierce competition. Multi-attribute decision models could be effectively utilized to solve the decision situations which can be encountered. 


\section{Bibliography}

[1] Al-adaileh R. M, An evaluation of information systems success: A user perspective - the case of Jordan Telecom group, European Journal of Scientific Research, 37(2):226-239, 2009

[2] Agouram H., Defining information system success in Germany, International Journal of Information Management, 29:129-137, 2009

[3] Bizoi, M., Sisteme support pentru decizii bazate pe comunicatii (Communication-Based Decision Support Systems), Ph.D. Thesis, (in Romanian), (http://www.racai.ro /Doctorate/Bizoi_Rezumat_teza.pdf, 2010, accessed on 09.07.2011)

[4] Carraro G., Chong F., Software as a Service (SaaS): An Enterprise Perspective, MSDN Library (http://msdn.microsoft.com/en-us/library/aa905332.aspx, 2006, accessed on 09.02.2012)

[5] Cojocaru S., Interfete inteligente ("Intelligent Interfaces"), in [9], pp. 213-215, 2007

[6] Filip F. G. , Towards more humanized real-time decision support systems, In Balanced Automation Systems: Architectures and Design Methods (L. Camarinha-Matos, H. Afsarmanesh, eds), Chapman \& Hall, London, pp. 230-240, 1995

[7] Filip F.G., Decizie asistata de calculator; decizii, decidenti, metode de baza si instrumente informatice associate ("Computer-Aided Decision-Making; Decisions, Decision-Makers, Basic Methods and Software Tools"), 2nd Edition, Editura Tehnica, Bucuresti(in Romanian), 2005

[8] Filip F. G., Sisteme support pentru decizii ("Decision Support Systems"), 2nd Edition, Editura Tehnica, Bucuresti (in Romanian), 2007

[9] Filip F.G., Designing and building modern information systems: a series of decisions to be made, Computer Science Journal of Moldova, 119-129, 2011

[10] Hamilton S., Chervany N.L., Evaluating Information System Effectiveness - Part I: Comparing Evaluation Approaches, MIS Quarterly, 5(3):55-69, 1981

[11] Hine J., Laliberte B., Enabling IT as a Service, White Paper. ESG (http://www.cisco. com/en/US/prod/collateral/netmgtsw/ps6505/ps11869/esg_enabling_it.pdf, 2011

[12] Gaindric C., Luarea deciziilor: metode si tehnologii ("Decision Making: Methods and Technologies"), Editura Stiinta, Chisinau (in Romanian), 1998

[13] ISO 9241 Ergonomics of human-system interaction, 2012 http://www.iso.org/iso/search.htm?qt=9241\&sort=rel\&type=simple\&published $=$ on; $\quad$ accessed on 09.02.2012)

[14] Kolb D.A., Frohman A. L., An organization development approach to consulting, Sloan Management Review, 12(4):51-65, 1970

[15] Gang Kou, Yanqun Lu, Yi Peng, and Yong Shi, Evaluation of classification algorithms using CDM and Rank Correlation, International Journal of Information Technology 83 Decision Making, Vol. 11, Issue: 1, DOI: 10.1142/S0219622012004872, 2012.

[16] Moriso M., Tsoukias A., JusWare: a methology for evaluation and selection of software products, IEE Proc-Softw. Eng., 144(2):162-174, 1997 
[17] Ness D.N., Decision support systems: theory and design, In Wharton Office of Naval Research on DSS, Philadelphia, November, pp. 4-7, 1975

[18] PP: Project Perfect: Project Management Software, 2012 http://www.projectperfect.com.au/, 2012, accessed on 09.02.2012)

[19] Resteanu C., Somodi M., Alexe B., Multi-Attribute Decision-Making; E-course, ICI, Bucharest, 2007

[20] Shelly G. B., Cashmanan T. J., Rosenblatt H.J., Systems Analysis and Design, 8th Ed., Thomson Course Technology, Boston, Mass, 2010

[21] SR: Soft Resources: Empowering Software Decisions, 2012, (http://www.softresources.com/, accessed on 06.02.2012)

[22] Sprague jr. R. H., Carlson E. D., Building Effective Decision Support Systems, Prentice Hall, Englewood Cliffs, N. J., 1982

[23] Suduc A.M., Interfete avansate pentru sisteme support pentru decizii("Advanced Interfaces for DSS"), PhD Thesis, (in Romanian), 2010 (http://www.racai.ro/Doctorate/Suduc_Rezumat_teza.pdf, accessed on 09.07.2011)

[24] TEC: Technology Evaluation Center, 2011, (http://www.technologyevaluation.com/software/, accessed on 09.07.2011)

[25] Trumba , White Paper: Five Benefits of Software as a Service, 2007 (http://www.trumba.com/ connect/knowledgecenter/software_as_a_service.aspx, accessed on 09.02.2012)

[26] Vernadat A., Enterprise Modeling and Integration Principles and Applications, Chapman \& Hall, London, 1996

[27] Vlahavas I., Stamelos Refanidis I., Tsoukias A., ESSE: an expert system for software evaluation, Knowledge-Based Systems, 12(4):183-197, 1999 